Pre-publication version of Cluley, R. and S.D. Brown 2014. The dividualised consumer: Sketching the new mask of the consumer. Journal of Marketing Management, DOI: 10.1080/0267257X.2014.958518

\title{
The Dividualised Consumer: Sketching the New Mask of the Consumer
}

\author{
Robert Cluley, Nottingham University Business School, University of \\ Nottingham, UK \\ Steven D Brown, School of Management, University of Leicester, UK
}

\begin{abstract}
Recent online marketing innovations such as ad-servers, ad-networks and ad-exchanges allow marketers to extract value from consumer data in new ways. But these new market devices just do not exploit technological innovations. They are constructed around a revolutionary new mask of the consumer. They treat consumers not as fixed individuals but as dividualised consumers - that is to say, collections of data that can be exposed, dissected and segmented into new marketable groups. After sketching out how marketing devices and theories have worked to define new marketplace behaviours, the paper turns to Deleuze's explanation of control societies to consider the social implications of these new marketing techniques within societies that are increasingly mediated through networked relationships.
\end{abstract}

Keywords ad-networks; ad-exchanges; dividual; Deleuze; online marketing

\section{Introduction}

After many fits and starts, booms and burst bubbles, a new online marketing ecosystem has developed over the last 20 years to allow marketers to understand and communicate with the marketplace in entirely new ways. New marketing techniques, devices and organisations have emerged that allow marketers to direct their resources to the most important, profitable and influential consumers. They allow marketers to capture fine-grained data about consumers' interests, activities and histories, to constantly analyse that data to produce distinct marketable segments and to efficiently purchase the right to present those segments with relevant marketing communications. While offering new opportunities for marketers to target their offerings to specific groups of consumers, the emergence of these technologies presents significant challenges for marketing and consumer researchers. They challenge the commonplace understandings of how marketing adds value (Benneman \& Schröder, 2002; Dholakia, Dholakia, \& Laub, 2002; Zwick \& Denegri Knott,2009), the role of marketing in the media environment (Pariser, 2011) and the role of marketing within social relations (Dholakia \& Dholakia, 2002; Hardt \& Negri, 2001; Turow, 2011). These technologies also invite us to imagine a new mask that renders the consuming subject in a manageable state (Tsing, 2009).

While traditional marketing techniques have placed different masks on consumers - reconstructing them as rational decision-makers, information processors, communicators, rebels, activists, workers and prosumers and so on they have all approached the consumer as an individual subject (see Gabriel \& Lang, 2008). The new marketing technologies described in this paper are different. They adopt an entirely new perspective on not only who but also what the consumer is. They construct impressions of consumers out of clustered data 
Pre-publication version of Cluley, R. and S.D. Brown 2014. The dividualised consumer: Sketching the new mask of the consumer. Journal of Marketing Management, DOI: 10.1080/0267257X.2014.958518

points of disembodied interests, behaviours, opinions and demographics (Zwick \& Dholakia, 2004a). Markets are, as a result, not broken up into individual consumers but increasingly are constructed out of components extracted from anonymous and aggregated consumer data (Zwick \& Denegri Knott, 2009). Rather than segments of one (Dibb, 2001), therefore, we have seen the emergence of segments of less than one. Such segments are not adequately described by treating marketing as the imposition of a representational framework, or mask, on the individual consumer. There is no need to imagine a consuming subject anterior to the assembled data traces.

This raises two interrelated questions. First, how are these data traces gathered together? Second, how do people become recruited into this performance of self as an assembly of data traces? Or put slightly differently, how do marketing practices enable people to recognise themselves as constituted by the data they generate on a daily basis? Notions of performativity are, we argue, absolutely central to adequately addressing these problems. Extant research turns to concepts of power to explain how consumers are recruited into these marketing techniques through disciplining technologies of the self which force particular masks on to consumers. However, this misrepresents the nature of subjectivity that lies at the heart of contemporary marketing. To appreciate this subjectivity we must do away with the idea that the masks put on consumers by marketers exist ready and waiting to be taken off the shelf. Following Pridmore and Zwick (2011), Zwick and Denegri Knott (2009), then, we argue that marketing renders the consuming subject as a dividual. This term is derived from the work of Deleuze (1992). It names a cybernetic subject made up of data point, codes and passwords. Unlike the extant engagement with Deleuze's concept within marketing and consumer research, though, we will argue that a concept of performativity is essential to capturing the nature of dividuality.

Our argument will be organised as follows. We first of all make the case that a 'performative' analysis of new marketing practices does not need recourse to a model of power or subjectivity that is external to the practices themselves. That is to say, the model of the consumer here is 'self-grounded'. We then progressively describe the development of internet and data-driven approaches in marketing and set out the ways in which they have eroded the concept of the individual consumer as the foundation of marketing practice. In the concluding sections, we develop Deleuze's notion of the dividual to explore how consumers are recruited into an understanding of themselves as data patterns.

\section{Self-grounding}

Social science often uses a high-level category to reframe a particular social phenomenon. For example, the application of Foucault's work to marketing usually involves positing a field of power relations as the (pre-existing) driving force within the relationship between consumers and marketing practices (see Humphreys, 2006). To say that we do not necessarily need to invoke some external category - such as power - to explicate this relationship is precisely what the idea of performativity invites us to do. Rather than appeal to factors, structure or forces that are outside the field of study, it treats the phenomenon 
Pre-publication version of Cluley, R. and S.D. Brown 2014. The dividualised consumer: Sketching the new mask of the consumer. Journal of Marketing Management, DOI: 10.1080/0267257X.2014.958518

as emergent from its own practice.

The roots of this approach lay with a conceptual turn in the ordinary language philosophy of Wittgenstein (1953) and Ryle (1953) and the subsequent speech act theory of Austin (1962) and Searle (1969). These philosophies of language attempted to overcome the apparent dead-end one wanders down when positing an external logical framework with which to fix the proper meaning of linguistic terms. The way out of this dead-end, for ordinary language thinkers at least, was to see meaning as produced in the course of the act of enunciation itself and the sequence of actions in which it is entangled rather than in some exterior structure. Meaning is, in this sense, self-grounding. It emerges as an utterance is fitted into social acts. Austin's (1962) well-known work on 'speech acts', from which the notion performative utterances is primarily derived, captures this selfgrounding character well. Austin demonstrates how utterances may accomplish social acts 'indirectly' (e.g. stating 'it is rather warm in this room' as an implicit request to open a window). He contrasts these with other acts that are accomplished through the very act of being said (e.g. when the priest declares as couple to be married, the saying of the words effects the change of social status in that instant). This latter example highlights an important aspect of such selfgrounding. Clearly, the priest's words only bring about this effect when they are supported by the institutional framework of the church, laws around marriage, along with the professional standing of the individual, not to mention the political economy and social stratification of power within a given society. But this does not mean that the meaning of the utterance is derived from somewhere outside of the act of being said, rather a web of relations affords the utterance its performative power.

Butler's $(1990,1992)$ work demonstrates the utility of these philosophical arguments to social science. Butler theorises gender and identity as qualities that are produced and stabilised through interactional processes rather than as clearly defined substances that precede their own performance. Clearly, gender is related to embodiment since having a body that is biologically marked as either 'female' or 'male' contributes towards the performance of gender - but embodiment is no more the grounds in which the meaning of gender is to be found than the priest's robes are the source of the meaning of the declaration of marriage. The meaning of gender is found in the ways it is done. In this sense, Butler also draws out the problem of agency. In some way, we are obliged to perform ourselves as gendered beings and the resources with which we can do so are clearly circumscribed socially, culturally and historically. Over time, performances can configure these resources in ways that are creative and transformative for both the people engaged in the performance and the broader cultural relations in which they are accomplished. But even these transformations are grounded in the resources they perform.

Following this, Callon's work treats markets and consumption activities as hybrid mixtures of people and things that constitute 'value' and 'preferences' from within their own interactions (see Callon, 2005; Callon, Méadel, \& Rabeharisoa, 2002). In doing so, it builds upon his earlier contributions to the 
Pre-publication version of Cluley, R. and S.D. Brown 2014. The dividualised consumer: Sketching the new mask of the consumer. Journal of Marketing Management, DOI: 10.1080/0267257X.2014.958518

social studies of science and technology which rejected the idea that the demarcation between 'good' and 'bad' science could be derived logically (see Callon, 1980, 1986). Instead, Callon and colleagues demonstrate that what counts as a scientific or a technical problem emerges from within webs of shifting semiotic and material relations between a wide variety of actors in networks that include the human and non-human. Like Butler, then, Callon argues that agency operates in complex ways within these relational networks of performativity.

Applied to marketing, the performative approach adopted by Callon allows us to suspend the idea of there being a clearly defined entity of 'the consumer' who preexists their engagement with markets. For example, when a person enters into a supermarket to make a purchase, they become part of an extensive network of relations that 'qualify' the value of products through processes of design, placement, production, pricing etc. The person becomes performed as a 'consumer' within these relations. This does not, of course, mean that the person is a blank slate who brings nothing to the encounter. They bring their own experiences and resources that assist in the activity, ranging from shopping lists and media recommendations to socially formed tastes and preferences. However, the tying together of these experiences and resources as a complex socio-cognitive performance occurs within the consumption activity itself, as part of the engagement with the network of qualifying devices. The idea of a 'consumer' is an effect rather than condition of the activity.

Notwithstanding the recent airing of differences between these approaches (see Butler, 2010; Callon, 2010), we will use these ideas of performativity to show how contemporary marketing practices make up people - to borrow Hacking's (2006) well-known phrase - and how people themselves participate in this act of making. Just as gender, for Butler, and markets, for Callon, are self-grounding, so we will argue that the contemporary consumer is performed by modern marketing devices and theories. They do not wear a mask of any kind - they are constituted by the way they are performed in data traces. To demonstrate this, in the proceeding sections we will explore how a new consuming subjectivity has been produced through technological developments that have afforded and been enabled by changes in marketing theory.

\section{From the internet to the web}

In May 1993, Schrage published a thought-piece in Adweek, entitled 'The Ultimate Network'. Here, Schrage brought the web to the attention of advertisers and marketers. Indeed, he argued that it was their future. The web, itself, was not long in the womb. Ironically, given its subsequent popularity and egalitarian principles, the web emerged as a response to a problem specific for a single, and very unique, organisation. This organisation was the European Centre for Nuclear Research (CERN) located in Switzerland. There was a high-level of churn among researchers at CERN. They would typically visit from universities and research centres for 2-year appointments, after which they would return to their host institutions (Naughton, 2012). Unfortunately, they often took their advances with them - primarily because there was no effective knowledge management 
Pre-publication version of Cluley, R. and S.D. Brown 2014. The dividualised consumer: Sketching the new mask of the consumer. Journal of Marketing Management, DOI: 10.1080/0267257X.2014.958518

system designed to capture their work and allow others to access it after they had left (Naughton, 2000). So, using existing technologies such as hypertext that allowed links to be made within and between documents stored on distinct computers, a group headed by Tim Berners-Lee constructed a system to deal with this unique knowledge management issue. Their initial goal was to develop a network that could store the information that was generated as CERN but Berners-Lee believed that this network would only function if it was designed to allow its users to shape it. Structurally, then, the web was set-up as a host-client network where hosts would store information and make it available for clients to request, edit and link to at any time. No one person or organisation was in control. Hosts could join the network without seeking permission from any central figure. The system 'was built on egalitarian principles' and encouraged 'thousands of individuals, universities and companies [to work], both independently and together' (Berners-Lee, 2010, p. 80). It was, as Raymond (2001) put it, a bazaar not a cathedral.

This system was made public in 1991 and its openness proved attractive. By 1993, Schrage observed: 'Virtually every major university, corporation and government agency in the world is on it'. The lack of central control was an attraction for marketers and advertisers too. It meant that advertisers would no longer be dictated to by the media producers they had subsidised for decades. Schrage explained: "No one really "owns" it; no one really "manages" it ... The simple truth is that Internet is a living, breathing, global network that for the moment remains untouched and untapped by the likes of Murdoch, Malone, Turner, or even that nerd di tutti nerds, Bill Gates'. As such, by subsidising free content for consumers, marketers and advertisers could place themselves at the heart of the web and, if it continued to move to the heart of various form of social interaction, marketing would move there too. Indeed, while the web was growing, as with any network, it needed to continue to grow. It needed new hosts, new content and new servers. Advertising, Schrage argued, would be essential here because advertisers were not only used to giving their content away for free but also sponsoring others to produce content for them (see Petrova, 2011 for a discussion on the relationship between advertising and media independence). As such advertisers could 'subsidize network growth for computers just as it did for radio and television' (Schrage, 1993).

In this early stage in web history, then, we see the web emerge as a means of transforming a wide-reaching community, the scientific community at CERN, into a series of data traces such that the physical presence of individuals was less important than the patterns they contributed to a distributed network. The socio-technical architecture of the early web framed these data traces in ways that rendered them as a meaningful resource. To use Callon et al.'s (2002) term, we may say that Berners-Lee's web emerged as an 'apparatus of distributed cognition' - an entanglement of people, technologies and data acting together that qualified their interactions to produce value. Rather than see the development of the web as outcome of the clearly defined intentions on the part of a series of groups (including advertisers), we may instead see it as a network of relations through which identities, interests and forms of value begin to 
Pre-publication version of Cluley, R. and S.D. Brown 2014. The dividualised consumer: Sketching the new mask of the consumer. Journal of Marketing Management, DOI: 10.1080/0267257X.2014.958518

emerge.

However, at this stage, the web was not able to produce economic value. The web began was an anonymous network - it was 'stateless'. Surfing online was an essentially private act. There was no mechanism through which a host could identify who a client was. This became a problem for hosts as individual webpages were expanded into websites in which a single host offered a series of linked pages. It also proved a significant constraint on e-commerce. Without knowing who a customer was, online sales were almost impossible. You could only buy one thing at a time and had to re-enter all your payment and delivery information for every single purchase.

The solution to this problem was easy enough to implement. The web operated through standard protocol that determined how clients and hosts would speak to each other. They set out what a client would have to do to gain access to a host, how the host would communicate with the client and what access the client would have to give to the host in return for access. These protocol were initially defined by Berners-Lee and his colleagues but have been modified ever since through the open access W3 Foundation (http://www.w3.org/). By 1994, a mechanism was added to these protocol that would enable a host to identify a client: the Persistent Client State HTTP Cookie. A cookie (or magic cookie) was a term common among programmers. It referred to a small data file passed between programmes. The Persistent Client State HTTP Cookie, in particular, was a small data file that would be downloaded from a host onto a client when the client request access to a webpage served by the host. Being persistent and unique, this small file allowed the host to recognise the client at their next visit and as they moved across different pages of their website. Thanks to the cookie, clients now left a footprint as the travelled across webpages. The cookie was, Pariser (2011) explains, a sticky note a host website stuck on a client's forehead. From a marketing perspective, cookies marked a revolutionary new relationship with consumers that, like all revolutionary events, seemed far from revolutionary at the time. Cookies allowed hosts to store items in a unique shopping basket linked to a client and meant that clients did not need to re-enter personal information for every order. Indeed, this information could be stored by the host in their own databases and linked back to the client through a cookie whenever they visited a site. Discovering value in this store of data marks the next step in the evolution of online marketing.

\section{The value of data}

In the wake of the 'dotcom bubble', it became obvious that traditional approaches to advertising would not work online. This bubble was, largely, fuelled by the idea that all a web start-up needed was a large volume of clients or 'traffic'. Once traffic was in place, a site could be monetised by introducing advertising which, it was assumed, would be attracted by the potential size of a site's traffic. This assumption was grounded, for its part, on an offline model of advertising. Here, a newspaper, magazine or television show became more valuable when its audience grew. Early online advertisers were attracted by the novelty of the Internet but the advertising dollars never arrived. 
Pre-publication version of Cluley, R. and S.D. Brown 2014. The dividualised consumer: Sketching the new mask of the consumer. Journal of Marketing Management, DOI: 10.1080/0267257X.2014.958518

There are many reasons for this. On the demand side, many users turned away from websites when they introduced advertising and many sites could not generate the traffic they promised. On the supply side, though, decision-makers in the advertising industry became increasingly concerned with maximising their return on advertising investment. To do this, they wanted to be satisfied that they only paid to advertise to people who would be most likely to buy their products - 'you only want to advertise dog food to people who own dogs' one industry axiom succulently put it. Indeed, going forward, advertising and media accounts would be won by those media providers who could offer robust data about who was looking at ads and what they were doing on the basis of having seen them. As Turow (2011) explains, this was 'an age in which the clients with the biggest accounts - global corporations - were obsessed with quantifying their return on their marketing investments and demanding accountability from agencies' (p. 29).

Some of this information was available in the data stores enabled by cookies. Cookies helped sites to measure how many separate impressions they had - that is how many unique users had visited their pages - and to record click-through rates for adverts that were linked from a host's site to an advertiser's own webpage. But, while this was powerful information, individual sites could only view a small part of a user's online journey. They could still only describe a few footprints but not a trail. Given the increasing importance of audience data to advertisers and advertising agencies, it was not long before firms began to offer even more information to marketers. As Turow explains:

marketing entrepreneurs quickly realized that if they received permission to place cookies across sites, they could note what individual did after they went to one site. If a cookie were detected at one of the related sites, the marketers could serve an ad to that individual's screen in sync not only with the topic of the current website but with those visited previously. Data about what the cookie owner learned about the individual cookie could be added to the cookie (or stored on a server and linked to the cookie), and revenues could be shared with the participating sites. (Turow, 2011, p. 55)

As a result, from the late 1990s we saw the development of new online services that would help marketers to efficiently target advertising at specific consumers. First, we saw the development of ad-servers that hosted online advertisements as third parties. That is to say, they would serve adverts on a webpage they did not host so that, when a client viewed a webpage, the adverts on that page would be hosted by the ad-server not the page's host. For hosts, ad-servers would provide a single buyer for their advertising space. But, as third parties sitting within the host-client relationship, ad-servers could also use cookies to identify clients. Using what became known as third-party cookies, ad-servers could combine data about clients across different websites. The value of these offerings was illustrated in 2007 when Google purchased one of the leading ad-serving companies - Doubleclick - for a 3reported \$3.1 billion in cash (http://www.nytimes.com/2007/04/14/technology/14DoubleClick.html?_r=0). 
Pre-publication version of Cluley, R. and S.D. Brown 2014. The dividualised consumer: Sketching the new mask of the consumer. Journal of Marketing Management, DOI: 10.1080/0267257X.2014.958518

From here, new services developed called ad-networks to allow marketers not only to buy online media from a single source but to position their advertising alongside specific content. On ad-networks, advertising space would be grouped together in terms of the content of the webpages on which the adverts were shown. Advertisers were then able to purchase blocks of advertising space around these groupings - allowing them, crudely, to match their offering with their target audience. If they wanted to reach football fans, they could, for example, buy space from a number of football sites, forums and comment sections of football-related news stories simply by bidding for a relevant grouping on an ad-network. The network would split the advertising revenue with websites within that group and would take a portion of the advertising spend for their services.

Tying together the ability to track consumers across websites that ad-servers offered and the ability to target advertising to consumers offered by adnetworks, further new services known as ad-exchanges developed. These allowed marketers to buy advertising space for specific categories of users or clients. That is to say, unlike adnetworks, where advertisers bought the right to show their adverts alongside specific content, ad-exchanges allowed advertisers to buy the right to show their adverts to specific clients whatever the content of the webpages they happened to be viewing.

For this to happen, ad-exchanges had to be able to categorise individual users into marketable groups at amazing speeds. There were several ways to go about this. First, they could use demographic information such as a user's physical location - delivered as part of web protocol. They could also analyse the search terms that a user had entered to get to a particular webpage to illustrate that user's interests. They could also use behavioural data derived from analysing a user's online history. Through a process known as cookie matching they could then tie together a user's likely interests with a market offering. To facilitate this, ad-exchanges analyse the trail of cookies left on a user's computer to determine their interests and attitudes and then place them into a marketable segment. In 2011, researchers at Stanford accessed the segments on offer to advertisers by Epic Marketplace. The 'segments included menopause, getting pregnant, repairing bad credit, and debt relief ' (Mayer \& Mitchell, 2012, p. 3).

Cookies, ad-servers, ad-networks, ad-exchanges can be described as market devices (see Muniesa, Millo,\&Callon, 2007). They are technical instruments that tie people and things together to construct an economic space. They perform attachments and weave together disparate elements that would not otherwise co-exist. For example, the click that takes a user from an online newspaper article through an advertisement for improving credit scores is based on a sociotechnical network of cookie trails, analytics, marketing strategies and product placements that invites the user to attach themselves to a subjectivity of 'seeking second chances in life'. This subjectivity may never be explicitly stated during the course of the process, and it may never have existed in any coherent form for the user before they make the click. That is to say, it is 'self-grounded'. Subjectivity 
Pre-publication version of Cluley, R. and S.D. Brown 2014. The dividualised consumer: Sketching the new mask of the consumer. Journal of Marketing Management, DOI: 10.1080/0267257X.2014.958518

emerges through solicitation, the call to engage in a further set of behaviours that attaches itself to the data trail. The person is invited to make themselves up in a space of preferences and actions that is framed by the market devices.

Indeed, as the web has morphed into social media and migrated onto mobile technologies, it is no longer just an individual's online behaviour that weaves them into these systems of deconstruction and reconstruction. Social media pages allow marketers to make judgements about individuals on the basis of who their friends are. Indeed, Mayer and Mitchell (2012) report that 'the free online dating website OkCupid was sending to the data provider Lotame how often a user drinks, smokes, and does drugs' (p. 3). Websites such as 'Loopt and Foursquare, which broadcast a user's location from her mobile phone, provide advertisers with opportunities to reach consumers with targeted ads when they're out and about' (Pariser, 2011, p. 44). Marketers are looking to 'wearable technologies' to measure 'a customer's level of physical activity ... posture, sleep habits, or even virility' with the aim that 'a marketer could look at the data from this man's wearable devices, notice that he doesn't stray too far from his couch, and promote specials on the brand's potato chips just before the Bears game each Sunday' (Berkowitz, 2013). Perhaps unsurprisingly, therefore, marketers now describe themselves as 'digital anthropologists' who 'follow the consumer on and offline to find out 'how they are really living their lives' (Weaver quoted in Treffiletti, 2012, p. 128).

\section{Mass, niche, individual...}

While many of the developments discussed so far can be conceived simply as technological improvements offering solutions to practical problems, these developments have been shaped, fundamentally, by changes in marketing theory that they themselves have enabled. Ad-servers, ad-networks and ad-exchanges are not based on the idea of mass marketing - that is, designing a universal appeal - but on the idea that value emerges from targeting specific consumers with specific communications. As Turow (2011) puts it, these systems allow marketers to identify targets and waste. Demand is, in short, no longer equal. Fisher and Smith (2011) explain: 'Contemporary marketing theory and practice is premised on a major idea: some people matter more than others' (p. 39).

This follows a move, first, from mass to niche marketing (Kotler, 1989), then to individual marketing (Dibb, 2001), and now to what has been called postmodern marketing (Hardt \& Negri, 2001) in which marketing is taken to be a practice of creating difference rather than identifying similarities. Market segmentation in this form of marketing is no longer a simple procedure that involves dividing the marketplace into groups which map onto pre-existing categories - men, women, silver surfers, dog owners and so on. Rather, the market is now segmented into clusters that are quantifiably different from other clusters with new differences between clusters feeding into new calculations. This is, admittedly a subtle distinction but it is an important one. For an analogy, we can think of the difference between grouping together the contents of a bag of sweets into reds, oranges, purples and so on and solving a Rubik's Cube. The former is easy because placing a sweet into a group has no effect on the other 
Pre-publication version of Cluley, R. and S.D. Brown 2014. The dividualised consumer: Sketching the new mask of the consumer. Journal of Marketing Management, DOI: 10.1080/0267257X.2014.958518

sweets. The latter is difficult because each move has an effect on the rest of the cube. In this regard, Zwick and Dholakia (2004b) describe these techniques as narrating consumers - that is, making them up. The market, in this sense, does not exist outside of traces consumers leave within databases. There can never be an end point where segmentation is perfected. New differences emerge through segmentation that must be divided up again. If we take ad-exchanges, for example, here an individual marketer can buy the right to access not individual consumers but segments of consumers - clustered around the marketer's marketing strategy. This then shapes the marketing communications offered to this group of consumers which are, subsequently, measured and analysed, feeding back into further clustering of consumers. Turning the tables on the logic of segmentation here, Zwick and Denegri Knott (2009) explain that 'rather than adjusting the functionality of commodities to match consumer desires, marketers can now modulate, at very little cost and in real time, the functionality of consumers to match an existing commodity' (p. 238).

\section{... Dividual}

So, rather than imagine some menu of possible masks that marketing can place on consumers, we have to conceptualise a relationship where masks are constantly constituted through marketing and consumer constantly reassembled as new collections of difference. Here, Zwick and Dholakia (2004b) tell us that 'the processes that constitute consumers in electronic marketplaces as knowable and manageable identities ... alters the way individuals are constituted as consumer subjects in the market' (p. 34-39). In this regard, Zwick and Denegri Knott (2009) emphasise that consumers are produced as 'novel sets of consumers' by these technologies (emphasis added, p. 225). They continue:

computerized information networks that continuously integrate dispersed sites of information solicitation with simultaneous feedback loops do not produce stable and enclosed repositories of meaning such as "individuals", "individuality" and "identities", but dynamic and functional modulations of these, or what Deleuze (1992) calls “dividuals". (Zwick \& Denegri Knott, 2009, p. 235)

Deleuze sets out his concept of the dividual in response to Foucault's work on disciplinary power. Disciplinary societies exercised power by containment. They placed people in 'environments of enclosure' such as the school, factory, hospital or prison (Deleuze, 1992, p. 3-4). In these spaces, people learned their social position by being made aware of their individual abilities and capacities. The two poles of this disciplinary society are individuality, considered as a set package of characteristics, and the mass, treated as the sum total of possible types of packages. People were graded and their performance was calibrated as variance from a mean. Any gap between an individual's performance and the norm of the mass placed social pressured on people to police their own behaviour. But, for Deleuze (1992), modern societies increasingly exercise power in a different way. They work through control not discipline. Networks have replaced enclosed environments. They sort people into those with access and those denied access to information and opportunities. Networks do this by coding individuals into databanks and reconstructing them into particular segments that have differing 
Pre-publication version of Cluley, R. and S.D. Brown 2014. The dividualised consumer: Sketching the new mask of the consumer. Journal of Marketing Management, DOI: 10.1080/0267257X.2014.958518

rights of access. In Deleuze's (1992) words: 'The numerical language of control is made of codes that mark access to information, or reject it' (p. 6).

Deleuze (1992) argued that marketing stood at 'the centre or the "soul"' of 'the new model of power' (p. 6). The function of marketing in the new society of control is to identify data points and reconstruct data in clustered segments that define what products people have access to, what advertising offers are made to them and what content they see. We see a very literal example of this process within ad-exchanges. On these exchanges, individual consumers are anonymised as their behaviour translated into a series of aggregated data points, labels and markers out of which groups of consumer interests, behaviours and demands are constructed. As with other networks described by Deleuze, on ad-exchanges, cluster analysis has replaced measures of variance from the average. Indeed, it is worth emphasising that in societies of control the door is always left open. No one knows their place. While in disciplinary societies, social life involves a highly programmatic shifting between established position, in control societies, movement is everything:

In disciplinary societies you were always starting all over again (as you went from school to barracks, from barracks to factory), while in control societies you never finish anything - business, training, and military service being coexisting metastable states of a single modulation, a sort of universal transmutation. (Deleuze, 1992, p. 5)

If power puts things in place, control organises vectors and clusters of mobile, changing qualities. Clusters are constantly constructed and reconstructed using a combinatorial logic. We can see this in the way ad-networks and ad-exchanges operate, endlessly, through computer bots and algorithms. A consumer's position is fluid as new differences are sought out to place them into new segments. This coding process is, then, a process of framing and reframing. Societies of control work by coding people into data points and reconstructing these into segments. The technologies of control, unlike those of discipline, do not individualise people but divide them. They segment, position, target and retarget. Accordingly, Deleuze puts forward the concept of the dividual as the object of power in societies of control. The first step in this process of division is to imagine people not as individuals with emotions, attitudes, behaviours, but as data that can be divided and reassembled through analysis. The next is to engage technologies and devices that intervene in these data traces to produce new combinations of people, data and things. The final step is to attach persons to the newly qualified sets of preferences and actions that are distributed in this hybrid space. The dividual is 'universal transmutation' of the person into a selfgrounded object of control.

Deleuze had a relatively unique perspective on these processes. While, as we have seen, Schrage argued that the web was the future of marketing in 1993 - for Deleuze surfing online was the present even in the early 90 s. 'Everywhere surfing has already replaced the older sports', he wrote (1992, p. 5-6). France, where Deleuze was based, was an exception in this regard. In Britain, online 
Pre-publication version of Cluley, R. and S.D. Brown 2014. The dividualised consumer: Sketching the new mask of the consumer. Journal of Marketing Management, DOI: 10.1080/0267257X.2014.958518

advertising might have only amounted to ' 0.1 per cent of the total' advertising spend by 1997 (Fletcher, 2008, p. 224) but since the early 1980s, France had its own functioning online network, Minitel, on which users could communicate electronically, search for information and shop (Cats-Baril \& Jelassi, 1994). According to The Economist, by the 1990s, this network was 'part of everyday life in France' (Moulaison, 2004). In fact, by 'the end of 1994, 36\% of all French people aged over 15 had accessed Minitel’ (Hill, 1997, p. 33).

\section{Recruiting the dividual}

So, what are the implications of the dividual for marketing theory? Thus far, conceptualising the implications of the shift from disciplinary to control societies has presented challenges for marketing theorists. Humphreys (2006), for instance, argues that such database and online marketing technologies turn the consumer into a prisoner - understood through Foucault's concepts. Even Zwick and Denegri Knott (2009), in an otherwise flawless analysis of database marketing management, return to Foucault's analysis of the panopticon. They recognise that this model of power is not especially relevant - as they put it, 'theorizations of the role of surveillance and simulation technologies for economic value creation strategies need to be updated' (p. 225) - yet, they continue to anchor their analysis through disciplinary power which, Zwick and Dholakia (2004b) argue, 'are based on a model of identity developed for the physical world' (p. 33). Similarly, Zwick, Bonsu, and Darmody (2008) conceptualise consumer value creation more generally as a form of consumer governmentality - that is to say, a technique of disciplinary power exercised on the individual consumer. As they put it: 'More than any other prior management technique, the co-creation paradigm rests on the notion of customer control through increasingly individualized modes of relating' (Zwick et al., 2008, p. 182). In contrast, Zwick and Dholakia (2004b) tell us: 'with the rise of database technologies and electronically mediated communications, new forms of marketing power have emerged' (p. 32).

In this regard, we can return to the distinction Deleuze himself sets out between the control of dividuals and the discipline of individuals as set out by Foucault. Foucault's key insight, Deleuze (1992) tells us, was not exposing the mechanics of power that 'succeeded that of the societies of the sovereignty' but that he exposed 'the transience of this model' (p. 3). At the time that Foucault was writing, Deleuze (1992) explains, the disciplinary society 'was what we already no longer were, what we had ceased to be' (p. 3). For Deleuze, a new account of power needed to be formulated which built upon Foucault's view of power as relational. It needed to account for the emerging strategy of exercising control by putting everything into perpetual movement and transformation. Disciplinary societies operated by categorising and putting in place through establishing 'regimes of truth' through which individuals recognise who and what they are. The emerging control societies, by contrast, operate breaking up categories and place, based in the demand constant change and transformation. Power is exercised by manipulating and extracting value from parts or microassemblages, which are continuously combined and re-combined, plugged in and then disconnected from the circuits of capital and authority. 
Pre-publication version of Cluley, R. and S.D. Brown 2014. The dividualised consumer: Sketching the new mask of the consumer. Journal of Marketing Management, DOI: 10.1080/0267257X.2014.958518

The distinction between discipline and power plays out most clearly in the notion of resistance (Deleuze, 1995). An individual consumer wearing a mask designed by marketing devices and marketing theory can refuse to wear that mask. They might take on another, switching from the rational decision-maker to the hedonist, but they are able to take it off. The dividual, in contrast, cannot distinguish themselves from the way they are assembled in marketing techniques if they enter into the networked spaces where those techniques are at work. The sheer ubiquity of those spaces is salutary to note: any engagement with the internet, using a debit or credit card, having an electronic medical record, any form of air travel, being a registered voter, profiles on credit-scoring agencies etc. You do not have to be a dividual, no 'power relations' will make you become one. But increasingly you will find the effort to not perform yourself as a data trace is no less easier than choosing not to perform a gender. Resistance, for Deleuze (1992), is thus to be found in 'out-gaming' the combinatorial logic of control: find a way to move faster, discover a 'line of flight', become something utterly unrecognisable to the devices that continuously attach themselves to your movements.

Given the ubiquity of these networks within markets and social life, marketing can no longer been seen simply a technology of power. It is now a driving force for control. In this regard, for Pariser (2011), targeted advertising technologies make it harder for individuals to have shared experiences of collective events. He describes a filter bubble that surrounds each of us online - sifting out information that is deemed irrelevant to us on the basis of our past online behaviour and irrelevant to us for the marketers who subsidise much of that information in the first place. Marketing is, then, a practice that undermines cohesion. It pulls societies apart into data and reconstructs us as segments of less than one. Here, Zwick and Denegri Knott (2009) summarise: 'we need to conceive of customer databases as the factories of the 21st century' (p. 242). Just as management mediated the lives of workers, it is now marketing that mediates the lives of dividualised consumers.

But can this really be so? As we stated earlier, there are two separate, but interrelated questions here. The first - how marketing 'makes up people' seems relatively tractable. Our brief history of internet marketing and its emerging moves to the offline world has demonstrated that contemporary marketing practice no longer requires a model of the consuming subject that is outside of the colossal data patterns that people leave in the form cookie trails, Facebook profiles, like tags on social media, Twitter feeds, customer profitability computations and so on. Marketing devices make it possible to directly attach these data patterns to marketing strategies. Preferences, values and 'likes' emerge from within the calculative space performed by this direct intervention. It is unnecessary to posit some external wellspring of subjectivity to manage this space of entanglement and attachment. The consumer is entirely self-grounded in their attachment to consumption activities.

The second question - how people are recruited into the project of 'dividualising' 
Pre-publication version of Cluley, R. and S.D. Brown 2014. The dividualised consumer: Sketching the new mask of the consumer. Journal of Marketing Management, DOI: 10.1080/0267257X.2014.958518

- is more difficult to address, and will require substantial future empirical work. But we can say for now that it is clear that not many people would describe themselves as 'assemblies of data traces'. Self-descriptions are more likely to be framed in terms of traditional 'substance' based ways of thinking identity (e.g. in terms of personality, character development, traits etc). However, for practical purposes, when it comes to securing financial credit, applying for a job, using a passport, engaging with medical services or even simply using the internet, we all of us become at that moment packets of data that are rendered into economic, political and social calculative spaces. Moreover, we are continuously confronted with feedback in the form of evaluations and guidance on many of our activities, in the form of Facebook 'likes', Twitter 'retweets', Amazon 'suggestions', Tinder 'right swipes' and so on. There are very few services that we now engage with that are not also simultaneously evaluative, calculative spaces in which we are invited to participate and leave our data traces.

It is at this point that our reading of these marketing devices, and Deleuze, differs from that in the extant marketing literature. The dividiual is, we have argued, a being that is 'self-grounded' in its own performance. It is not a consumer mask that is worn. We can push this a little further. The logic of 'control societies' begins to find its way into how we think about association and subsequently how we think of ourselves. When your social worth is measured, in part, by the number of Facebook friends you have, or by the number of re-tweets your last Twitter posting gained, then you have already become attached to the project of dividualisation. The idea that our thinking is in part embedded in the technologies we use is now entirely commonplace. Part of us seems to die a little when we misplace our mobile phone, or - horror of horrors! - cannot find a wi-fi connection. We may perhaps resist the description of ourselves as operant data traces, but we most certainly rely upon these traces on a daily basis to sustain what we think we are.

In this paper, then, we have argued that new marketing devices that have been shaped by and shaped marketing theory, are based around a performance by the consumer. That is to say, these new marketing technologies are not imposed on the consumer but recruit the consumer in their very enactment. They do not exist without the consumer. So, whereas marketing has traditionally segmented the market through demographic variables such as gender, race, age and socioeconomic status to produce 'masks' that are fitted to groups of consumers, these new marketing techniques allow consumers to render themselves as clusters of data trails or 'dividuals'. Here, there is no meaningful distinction between the consuming subject and the mask through which they are represented in marketing practice. There is a 'self-grounding' performance of subjectivity that emerges from the entanglement of people, data and things. Marketing helps to bring into existence the subject it targets by framing a calculative economic space through the use of marketing devices. We are what we click.

\section{References}

Austin, J. L. (1962). How to do things with words: The William James Lectures 
Pre-publication version of Cluley, R. and S.D. Brown 2014. The dividualised consumer: Sketching the new mask of the consumer. Journal of Marketing Management, DOI: 10.1080/0267257X.2014.958518

delivered at Harvard University in 1955. In J. 0. Urmson \& M. Sbisà (Eds.), Oxford: Clarendon Press

Benneman, S., \& Schröder, J. (2002). Virtual communities as an instrument of internet marketing. In N. Dholakia, W. Fritz, R. R. Dholakia, \& N. Mundorf (Eds.), Global Ecommerce and online marketing: Watching the evolution. Westport, CT: Quorum Books.

Berkowitz, D. (2013). Wearable technology lets us track consumers' activity as never before. Retrieved November 1, 2013, from

http://adage.com/article/digitalnext/wearable-technology-newest-advertisingfrontier $/ 241211 / 615$

Berners-Lee, T. (2010). Long live the web. Scientific American, 80-85.

doi:10.1038/scientificamerican1210-80

Butler, J. (1990). Gender trouble: Feminism and the subversion of identity.

London: Routledge.

Butler, J. (1992). Bodies that matter: On the discursive limits of 'sex'. London: Routledge.

Butler, J. (2010). Performative agency. Journal of Cultural Economy, 3, 147-161. doi:10.1080/ 62017530350.2010.494117

Callon, M. (1980). Struggles and negotiations to define what is problematic and what is not:The socio-logic of translation. In K. D. Knorr, R. Krohn, \& R. Whitley (Eds.), The social process of scientific investigation: Sociology of sciences. Vol. IV. Dorderecht: D.Reidel.

Callon, M. (1986). Some elements of a sociology of translation: Domestification of the scallops and fishermen of St. Brieuc Bay. In J. Law (Ed.), Power, action, belief: A new sociology of knowledge? London: Routledge and Kegan Paul.

Callon, M. (2005). Why virtualism paves the way to political impotence: A reply to Daniel Miller's critique of the laws of the markets. Sociology: European

Electronic Newsletter, 6, 3-20.

Callon, M. (2010). Performativity, misfires and politics. Journal of Cultural Economy, 3(2), 163-169. doi:10.1080/17530350.2010.494119

Callon, M. (2010) 'Performativity, misfires and politics', Journal of Cultural Economy, 3(2):163-169. doi:10.1080/17530350.2010.494119

Callon,M.,Méadel, C.\&Rabeharisoa, V. (2002). The economy of qualities. Economy and Society, 31, 194-217. doi:10.1080/03085140220123126

Cats-Baril, W. L., \& Jelassi, T. (1994). The French videotex system Minitel: A successful implementation of a national information technology infrastructure. MIS Quarterly, 18, 1-20. doi:10.2307/249607

Deleuze, G. (1992). Postscript on the societies of control. October, 59, 3-7. Deleuze, G. (1995). Control and becoming. In G. Deleuze (Ed.), Negotiations (pp. 169-176). New York, NY: Columbia University Press.

Dholakia, N., \& Dholakia, R. R. (2002). Markets and marketing in the information age. In N. Dholakia, W. Fritz, R. R. Dholakia, \& N. Mundorf (Eds.), Global Ecommerce and online marketing: Watching the evolution. Westport, CT: Quorum Books.

Dholakia, N., Dholakia, R. R., \& Laub, M. (2002). Electronic commerce and the transformation of marketing. In N. Dholakia, W. Fritz, R. R. Dholakia, \& N. Mundorf (Eds.), Global E-commerce and online marketing: Watching the evolution. Westport, CT: Quorum Books. 
Pre-publication version of Cluley, R. and S.D. Brown 2014. The dividualised consumer: Sketching the new mask of the consumer. Journal of Marketing Management, DOI: 10.1080/0267257X.2014.958518

Dibb, S. (2001) 'New millennium, new segments: Moving towards the segment of one?', Journal of Strategic Marketing, 9. doi:10.1080/713775742

Fisher, D. \& Smith, S. (2011). Cocreation is chaotic: What it means for marketing when noone has control. Marketing Theory, 11, 325-350.

doi:10.1177/1470593111408179

Fletcher, W. (2008). Powers of persuasion: The inside story of British advertising. Oxford: Oxford University Press.

Gabriel, Y., \& Lang, T. (2008). New faces and new masks of today's consumer. Journal of Consumer Culture, 8, 321-340. doi:10.1177/1469540508095266 Hacking, I. (2006). Making up people. London Review of Books, 28, 23-26. Hardt, M., \& Negri, A. (2001). Empire. London: Harvard University Press. Humphreys, A. (2006). The consumer as Foucauldian "object of knowledge". Social Science Computer Review, 24, 296-309. doi:10.1177/0894439306287975 Kotler, P. (1989). From mass marketing to mass customization. Strategy and Leadership, 17, 10-47. doi:10.1108/eb054267

Mayer, J. R., \& Mitchell, J. C. (2012). Third-party web tracking: Policy and technology. Retrieved from https://cyberlaw.stanford.edu/files/publication/files/trackingsurvey12.pdf Moulaison, H. L. (2004). The Minitel and France's legacy of democratic information access. Government Information Quarterly, 21, 99-107. doi:10.1016/j.giq.2003.11.003

Muniesa, F., Millo, Y., \& Callon, M. (2007). Introduction. In Market devices. Oxford: Blackwell.

Naughton, J. (2000). A brief history of the future: Origins of the internet. London: Phoenix.

Naughton, J. (2012). From Gutenberg to Zuckerberg: What you really need to know about the internet. London: Quercus.

Pariser, E. (2011). The filter bubble: What the internet is hiding from you.

London: Viking.

Petrova, M. (2011). Newspapers and parties: How advertising revenues created an independent press. American Political Science Review, 105(4), 790-808. doi:10.1017/S0003055411000360

Pridmore, J., \& Zwick, D. (2011). Editorial: Marketing and the rise of commercial consumer surveillance. Surveillance \& Society, 8(3), 269-277.

Raymond, E. (2001). The cathedral and the bazaar. Retrieved from http://www.archive.org/stream/CathedralAndTheBazaar/cathedralbazaar_djvu.txt 680

Ryle, G. (1953). Ordinary language. The Philosophical Review, 62(2), 167-186. doi:10.2307/2182792

Schrage, M. (1993, May 17). The ultimate network. Adweek.

Searle, J. (1969). Speech acts. Cambridge: Cambridge University Press.

Treffiletti, C. R. (2012). Internet ad pioneers: The stories of the unsung people behind the birth and growth of the internet ad industry. Amazon.

Tsing, A. (2009). Supply chains and the human condition. Rethinking Marxism: A Journal of Economics, Culture \& Society, 21, 148-176.

doi:10.1080/08935690902743088

Turow, J. (2006). Niche envy: Marketing discrimination in the digital age. London: The M.I.T.Press. 
Pre-publication version of Cluley, R. and S.D. Brown 2014. The dividualised consumer: Sketching the new mask of the consumer. Journal of Marketing Management, DOI: 10.1080/0267257X.2014.958518

Turow, J. (2011). The daily you: How the new advertising industry is defining your identity and your worth. London: Yale.

Wittgenstein, L. (1953). Philosophical investigations. London: Blackwell.

Zwick, D., Bonsu, S. K., Darmody, A. (2008). Putting consumers to work: 'Cocreation ' and new marketing govern-mentality. Journal of Consumer Culture, 8(2), 163-196. doi:10.1177/1469540508090089

Zwick, D., \& Denegri Knott, J. (2009). Manufacturing customers: The database as new means of production. Journal of Consumer Culture, 9(2), 221-247.

doi:10.1177/1469540509104375

Zwick, D., \& Dholakia, N. (2004a). Consumer subjectivity in the Age of Internet: The radical concept of marketing control through customer relationship management. Information and Organization, 14, 211-236.

doi:10.1016/j.infoandorg.2004.01.002

Zwick, D., \& Dholakia, N. (2004b). Whose identity is it anyway? Consumer representation in the age of database marketing. Journal of Macromarketing, 24(1), 31-43. doi:10.1177/0276146704263920

Robert Cluley is a Lecturer in Marketing at Nottingham University Business School. His research sets out a social study of marketing - in which marketing is viewed as something people do to other people. His research has been published in leading academic journals including Organisation Studies, Organization and Marketing Theory. Corresponding author: Robert Cluley, Nottingham University Business School, University of Nottingham, UK robert.cluley@nottingham.ac.uk

Steven D. Brown is Professor of Social and Organisational Psychology at the University of Leicester. His research interests are around social and collective remembering, particularly within 'vulnerable' groups. He is author of The Social Psychology of Experience: Studies in Remembering and Forgetting (Sage, 2005, with David Middleton); Psychology without Foundations: History, Philosophy and Psychosocial Theory (Sage, 2009, with Paul Stenner) and Vital Memories: Affect, ethics and agency (Routledge, 2014, with Paula Reavey). s.d.brown@le.ac.uk 